\title{
ERYTHRODIPLAX LETICIA, SP.N. DE LIBÉLULA DO NORDESTE BRASILEIRO (ODONATA, LIBELLULIDAE)
}

\author{
Angelo B.M. Machado ${ }^{1}$
}

\begin{abstract}
ERYTHRODIPLAX LETICIA, N.SP. OF DRAGONFLY FROM NORTHEASTERN Brazil. (Odonata, Libel.lui.IDAE). Erythrodiplax leticia sp.n. is described based on nine male specimens, most of which collected at Chapada Diamantina, State of Bahia. The new species is close to Erythrodiplax fervida (Erichson, 1848) but differs from it by the size, venation, extension of the basal wing spots, and structure of the superior anal appendages.

KEY WORDS. Odonata, Libellulidae, Erythrodiplax, new species, Northeastern Brazil
\end{abstract}

Com distribuição predominantemente neotropical, o gênero Erythrodiplax Brauer, 1868 é o maior gênero americano da família Libellulidae, contendo atualmente 53 espécies (GARRISON 1991), das quais 39 já assinaladas no Brasil (TSUDA 1986). É interessante ressaltar que, decorridos 53 anos após a publicação da clássica monografia de BORROR (1942) sobre o gênero Erythrodiplax, apenas quatro espécies foram acrescentadas a este gênero, duas da Venezuela (BORROR 1957) e duas do Brasil (SANTOS 1946, 1956). Em recente viagem de coleta à região da Chapada Diamantina, no centro da Bahia, deparamos com um vistoso Erythrodiplax, facilmente caracterizado como uma nova espécie, que é agora descrita e ilustrada.

\section{Erythrodiplax leticia, sp.n.}

Figs 1-5

Descrição do macho. Coloração: lábio vermelho (holótipo) ou marrom. Labro, anteclípeo, pós-clípeo e porção anterior da fronte vermelhos (holótipo) ou castanho-avermelhados com uma pequena área amarelada próxima ao olho. Porção superior da fronte, vértex e occiput marrons. Protórax, pterotórax e patas marrons. Asas hialinas com grande mácula basal amarelo-pardo (Fig. 5), nas asas anteriores estendo-se à quarta $(22,2 \%)$, quinta $(55,6 \%)$ ou sexta $(22,2 \%)$ antenodal, às partes distais do subtriângulo $(10,5 \%)$, ou do triângulo $(42,2 \%)$, ou à primeira $(10,2 \%)$, segunda $(31,6 \%)$ ou terceira $(5,5 \%)$ célula distal ao triângulo. Nas asas posteriores, até à sexta $(10,5 \%)$, sétima $(10,5 \%)$, oitava $(68,5 \%)$ ou nona $(10,5 \%)$ antenodal, segunda $(12,5 \%)$, terceira $(31,2 \%)$, quarta $(37,5 \%)$, quinta $(12,5 \%)$

1) Departamento de Zoologia, Instituto de Ciências Biológicas. Universidade Federal de Minas Gerais. Caixa Postal 486, 31270-901 Belo Horizonte. Minas Gerais, Brasil. 
ou sexta $(6,3 \%)$ célula distal ao triângulo, primeira $(50,0 \%)$ ou segunda $(50,0 \%)$ célula distal à alça anal, quarta $(18,7 \%)$, quinta $(50,0 \%)$, sexta $(18,7 \%)$ ou sétima $(12,5 \%)$ célula no espaço entre CuP e A1. A parte distal da mácula amarelo-pardo contém sempre 1-2 fileiras de células com o centro claro. Nervura costal marrom, demais nervuras negras, exceto na área das máculas, onde são pardo-amareladas na face ventral das asas e brancas, na face dorsal (Fig. 5). Pterostigma castanhoamarelado. Abdômen vermelho (holótipo) ou castanho-avermelhado. Apêndices anais alaranjados.
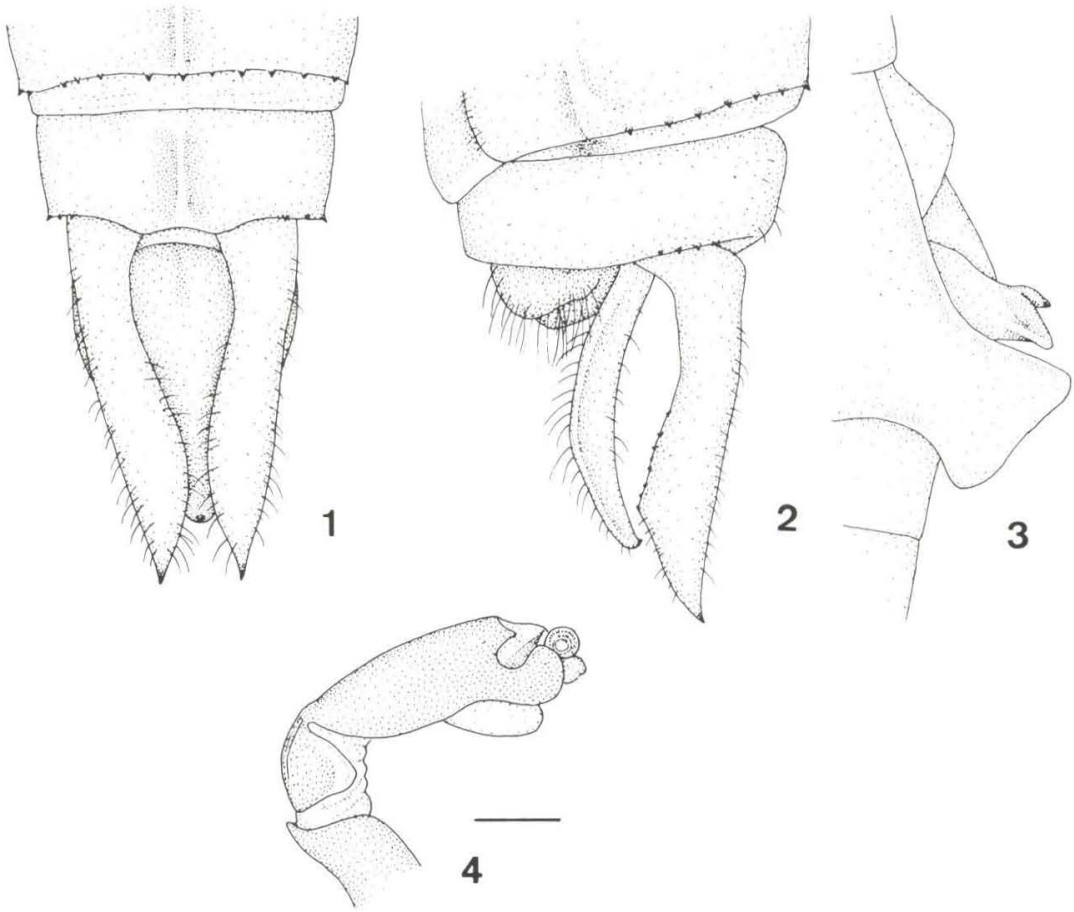

Figs 1-4. Erythrodiplax leticia, sp.n.. (1-3) Holótipo macho, apêndices anais em vista dorsal (1) e lateral (2); (3) genitália do segundo segmento em vista lateral; (4) parátipo, pênis em vista lateral. Barra $=0,5 \mathrm{~mm}$.

Nervação: antenodais na asa anterior $10.1 / 2(11,1 \%), 11.1 / 2(83,3 \%)$, $12.1 / 2(5,6 \%)$; na asa posterior $9(44,4 \%), 10(50,0 \%), 10.1 / 2(5.6 \%)$. Pós-nodais na asa anterior $7(5,6 \%), 8(44,4 \%), 9(44.4 \%), 10(5,6 \%)$; na asa posterior 8 $(11,1 \%), 9(66,7 \%), 10(22,2 \%)$. Triângulo na asa anterior atravessado $(100 \%)$; na asa posterior livre (100\%). Subtriângulo com três células (100\%). Campo discoidal na asa anterior com três séries de células numa distância de 9-13 células, seguindo-se quatro séries numa distância de 1-5 células, com 5-6 células na margem $(43,7 \%)$ ou com três séries de células numa distância de 2-5 células, seguindo-se duas séries numa distância de 1-4 células e um número crescente de séries até 5-10 



Figs 5-6. (5) Erythrodiplax leticia sp.n., parátipo, Iraquara, Bahia; (6) Erythrodiplax fervida. Soledad, Cuba. $(x 1,57)$ 
na margem $(56,4 \%)$. Campo discoidal na asa posterior com duas séries de células numa distância de 3-5 células, seguindo-se três séries de células numa distância de 2-3 células e um número crescente de células até 10-13 na margem. Rspl na asa anterior com cinco $(66,7 \%)$ ou seis $(33,3 \%)$ células; na asa posterior com cinco $(77,8 \%)$ ou seis $(22,2 \%)$. Mspl na asa anterior totalmente ausente $(66,7 \%)$ ou pouco delimitado $(33,3 \%)$; na asa posterior ausente $(81,8 \%)$ ou presente $(18,2 \%)$ com 4-5 células. Cu-a na asa anterior $1(100 \%)$; na asa posterior $1(94,4 \%)$ ou dois $(5,6 \%)$. CuP na asa posterior originando-se no ângulo anal do triângulo $(100 \%)$. Alça anal em forma de pé, com célula intercalar presente $(52,9 \%)$ ou ausente (47.1) no calcanhar e ausente no canto anal do triângulo (100\%), com 34 $(5,6 \%), 35(11,0 \%), 36(22,1 \%), 37(5,6 \%), 38(28,0 \%), 39(5,6 \%), 40(5,6 \%)$, $41(11,0 \%)$, ou $42(5,6 \%)$ células. Base da alça anal, entre A1 e A2, com quatro $(66,7 \%)$ ou cinco $(33,3 \%)$ células.

Outros caracteres. Fronte com quina anterior arredondada, porção superior com furca mediana profunda. Vértex com dois tubérculos pequenos. Lobo posterior do protórax aproximadamente quadrado, com ângulos distais arredondados, ligeiramente estreitado na base. Fêmures posteriores com 10-14 espinhos de tamanhos crescentes, sendo o último o dobro do penúltimo. Apêndices anais superiores (Figs 1-2) com uma fileira de 7-9 dentículos (Fig. 2), estendendo-se anteriormente até à metade do apêndice. Genitália do segundo segmento como na figura 3. Pênis como na figura 4 .

Medidas ( $\mathrm{mm}$, intervalo de variação e média): asa anterior, comprimento 26,2-31,5, média 29,8, largura máxima 6,5-7,2, média 6,9; asa posterior, comprimento 26,0-30,5, média 28,9, largura máxima 8,5-10,2, média 9,7; abdômen 20,0-24,0, média 23,0; pterostigma 3,1-3,7, média 3,5.

Fêmea: desconhecida

Holótipo macho. Brasil, Bahia: Iraquara (Lagoa da Pratinha, 700m, Fazenda da Pratinha, Chapada Diamantina), 20-IV-95, A. Machado, P.A. Machado \& E. Machado leg. Parátipos: cinco machos de mesma procedência, data e coletores. Bahia: Juciape, 400m, um macho, 23-IV-95, A. Machado, P.A. Machado \& E. Machado leg.; Paraíba: Campina Grande (Km 32 da estrada João Pessoa-Campina Grande), dois machos, 07-I-60, J. Evangelista leg. Total: nove machos. Holótipo e sete parátipos depositados na coleção do autor em Belo Horizonte. Um parátipo depositado na coleção do Departamento de Zoologia do Instituto de Ciências Biológicas (Universidade Federal de Minas Gerais), Belo Horizonte.

Discussão. Erythrodiplax leticia, sp.n. enquadra-se no grupo unimaculata de Borror (1942), integrando-se, pelas características do pênis e do lobo genital, no subgrupo que contém E. ochracea (Burmeister, 1839), E. fervida (Erichson, 1848), E. unimaculata (De Geer, 1773), E. parvimaculata Borror, 1942, E. laurentia Borror, 1942 e E. kimminsi Borror, 1942. Nesse subgrupo, aproxima-se de E. fervida, da qual se distingue principalmente pela maior extensão das máculas basais das duas asas. No gênero Erythrodiplax, essa extensão é superada apenas em E. solimaea Ris, 1911 e E. funerea (Hagen, 1861) cujas máculas basais atingem ou ultrapassam o nível do nódus. As figuras 5-6 permitem comparar a extensão 
das máculas basais de $E$. fervida e E. leticia e mostram ainda a presença de nervuras brancas nas máculas desta última espécie. E. leticia difere ainda de E. fervida por seu maior tamanho, pelos dentículos ventrais dos apêndices anais superiores, que se estendem anteriormente até o $1 / 3$ distal do apêndice em $E$. fervida e até sua metade em E. leticia e por alguns aspectos da área anal das asas posteriores. Assim, o número de células na alça anal é 34-42 em leticia e 18-27 em fervida (dado obtido da análise de oito asas). Do mesmo modo, o número de células entre A1 e A2, na base da alça anal, é quatro (66.7\%) ou cinco (33.3\%) em leticia e dois $(86 \%)$ ou três (14\%) em fervida [dado obtido de BORROR (1942), com base em 67 machos]. A largura máxima da área anal é também maior em leticia $(8,5-10,2$, média 9,7) do que em fervida $(8,3-8,6$, média 8,4).

Cabe lembrar ainda que, do ponto de vista zoogeográfico, E. leticia ocorre no nordeste do Brasil e $E$. fervida no norte da América do Sul até o México e nas Antilhas, não tendo ainda sido assinalada na Amazônia.

Dados ecológicos: a maioria dos exemplares estudados foi coletada na Lagoa da Pratinha, formada por represamento da água que nasce na gruta de mesmo nome e segue até o Rio Preto. Com cerca de $250 \mathrm{~m}$ de comprimento, $50 \mathrm{~m}$ de largura e profundidade não excedendo a $1,5 \mathrm{~m}$, a lagoa tem águas límpidas, fundo arenoso rico em conchas de moluscos, sendo relativamente pobre em macrófitas. E. leticia era freqüente na vegetação marginal, podendo ser encontrada também a alguma distância da lagoa, pousada no chão próximo à vegetação de caatinga. O exemplar coletado em Juciape estava pousado em uma pedra próxima a uma pequena cachoeira. Uma busca cuidadosa no vasto material de Erythrodiplax ainda não identificado da coleção do autor revelou a presença de dois exemplares machos provenientes de Campina Grande, Paraíba. Isso amplia consideravelmente a área de distribuição da espécie, que, provavelmente, é endêmica do nordeste brasileiro. O encontro, no nordeste, de uma espécie tão vistosa e ainda não descrita mostra que a biodiversidade da região ainda é muito pouco conhecida.

Dedico essa libélula à minha primeira neta, Letícia, nascida poucos dias após a descoberta da espécie na Lagoa da Pratinha, na Bahia.

AGRADECIMENTOS. A Paulo Augusto Ribeiro Machado e Eduardo Ribeiro Machado, pela ajuda na coleta do material durante viagem à Chapada Diamantina. Bahia: a Myrian Morato Duarte. pelos desenhos que ilustram este trabalho.

\section{REFERÊNCIAS BIBLIOGRÁFICAS}

BORROR, D.J. 1942. A revision of the libelluline genus Erythrodiplax (Odonata). Contributions in Zoology and Entomology No. 4, Biological Series. Graduate school studies. Columbus, The Ohio State University, XV-A+286p. 1957. New Erythrodiplax from Venezuela (Odonata. Libellulidae). Acta Biol. Venez. 2 (5): 31-42.

Garrison, R.W. 1991. A synonymic list of the New World Odonata. Argia 3 (2): $1-30$. 
SAnTos, N.D. 1946. Contribuição ao conhecimento da fauna de Pirassununga, Estado de S. Paulo. III: Descrição de "Erythrodiplax gomesi" N.SP. (Odonata: Libellulidae) Rev. Brasil. Biol. 6 (1): 33-37. 1956: Erythrodiplax luteofrons N.SP. (Odonata: Libellulidae). Bol. Mus. Nac. Rio de Janeiro (Zool.) 141: 1-5.

TsudA, S. 1986. A distributional List of World Odonata. Osaka, Edição do autor, 246p.

Recebido em 11.XI.1995; aceito em 14.IV.1996. 